\title{
Effects of the spatial configuration of trees on urban heat mitigation: A comparative study
}

\author{
Weiqi Zhou ${ }^{\mathrm{a}, \mathrm{b}, *}$, Jia Wang ${ }^{\mathrm{a}, \mathrm{b}}$, Mary L. Cadenasso ${ }^{\mathrm{c}}$ \\ a State Key Laboratory of Urban and Regional Ecology, Research Center for Eco-Environmental Sciences, Chinese Academy of Sciences, No. 18 Shuangqing Road, Beijing 100085, China \\ ${ }^{\mathrm{b}}$ University of Chinese Academy of Sciences, No. 19A Yuquan Road, Beijing 100049, China \\ c Department of Plant Sciences, University of California, Davis, One Shields Ave., Davis, CA 95616, USA
}

\section{A R T I C L E I N F O}

\section{Article history:}

Received 2 June 2016

Received in revised form 22 March 2017

Accepted 30 March 2017

Available online 13 April 2017

\section{Keywords:}

Urban tree canopy

Spatial configuration

Urban heat mitigation

Urban ecology

Baltimore

Sacramento

\begin{abstract}
A B S T R A C T
Urban greenspace has significant cooling effects on urban heat. Recent studies investigating the effects of spatial configuration of greenspace show significant, but inconsistent results, including both positive and negative effects. To investigate the causes of this inconsistency, we compared Baltimore, MD and Sacramento, CA, USA, two cities with very different climatic conditions. We quantified and compared the relationships between the spatial configuration of trees and land surface temperature (LST) using different statistical approaches, and conducted the analyses using spatial units of different sizes, based on trees mapped from $1 \mathrm{~m}$ high resolution imagery. We found: (1) trees' cooling efficiency was higher in Baltimore than in hotter and drier Sacramento. Additionally, percent cover of trees was more important than their spatial configuration in predicting LST in Baltimore, but the opposite was found in Sacramento. (2) Spatial configuration of trees affects LST more in Sacramento than in Baltimore, and the effects of spatial configuration of trees on LST varied greatly in terms of magnitude, significance, and even direction, between the two cities. Notably, mean patch size had significantly positive effects on LST in Baltimore, but negative effects in Sacramento. In contrast, edge density had negative effects on LST in Baltimore, but positive effects in Sacramento. (3) Different statistical approaches resulted in dramatic changes in the relationships between LST and configuration metrics. Our results underscore the necessity of controlling the effects of percent cover of trees, when quantifying the effects of spatial configuration of trees on LST. (4) Spatial autocorrelation may influence relationships between landscape metrics and LST, particularly when the unit of analysis is relatively small. (5) The relationships between spatial configuration metrics and LST are stronger with an increase of the size of the analytical unit. This study can enhance our understanding of the effects of spatial configuration of greenspace on urban heat island (UHI). It also provides important insights to urban planners and natural resource managers on how to mitigate the impact of urbanization on UHI through urban design and vegetation management.
\end{abstract}

(c) 2017 Elsevier Inc. All rights reserved.

\section{Introduction}

Urban heat island (UHI) describes the phenomenon by which urban areas are warmer than surrounding non-urban areas (Voogt and Oke, 2003). Increased temperatures due to the UHI effect may increase water consumption and energy use in urban areas (Santamouris et al., 2015; Wan et al., 2012), alter species composition and distribution (Niemelä, 1999; White et al., 2002), and lead to an increase in the production of ground level ozone which has direct consequences for human health (Akbari et al., 2001; Akbari et al., 1996). In addition, excess heat affects the comfort of urban dwellers and leads to greater health risks (Poumadere et al., 2005). In fact, extreme heat increases

\footnotetext{
* Corresponding author at: State Key Laboratory of Urban and Regional Ecology, Research Center for Eco-environmental Sciences, Chinese Academy of Sciences, No. 18 Shuangqing Road, Beijing 100085, China.

E-mail address: wzhou@rcees.ac.cn (W. Zhou).
}

mortality and morbidity in cities worldwide (Fouillet et al., 2006; Harlan and Ruddell, 2011). Consequently, how to mitigate and adapt to the UHI has become a major research focus in urban climatology and urban ecology (Arnfield, 2003; Sun and Chen, 2017; Weng, 2009; Zhou et al., 2011).

Considerable research has demonstrated the significant cooling effects of urban greenspace on urban heat (Fan et al., 2015; Jenerette et al., 2007; Kong et al., 2014; Li et al., 2016; Ma et al., 2010; Weng et al., 2004; Zhou et al., 2011). Increasing the percent cover of greenspace can greatly reduce ambient air temperatures and land surface temperatures (Bowler et al., 2010; Connors et al., 2013; Fan et al., 2015; Li et al., 2012; Weng et al., 2004; Zhou et al., 2011; Zhou et al., 2014). In addition, the spatial configuration (or arrangement) of greenspace, can also have significant effects on land surface temperature (LST) (Chen et al., 2014; Fan et al., 2015; Kong et al., 2014; Li et al., 2013b; Li et al., 2012; Maimaitiyiming et al., 2014; Myint et al., 2015; Zhou et al., 2011). Because cities have limited space for greening, managers and decision- 
makers would benefit from knowing how to optimize the spatial configuration of greenspace to further alleviate urban heat stress (Huang et al., 2011; Li et al., 2016; Myint et al., 2015; Zhou et al., 2011).

We know that simply increasing the percent cover of greenspace leads to a reduction of temperatures; this relationship is very consistent. What is less known, however, is the effects of the spatial configuration of that greenspace on urban temperatures. Research results are, in some cases, contradictory. For example, greater patch density of greenspace reduced LST in studies conducted in Shenzhen (Li et al., 2010) and Shanghai, China (Li et al., 2011), Baltimore, USA (Zhou et al., 2011), and Berlin, Germany (Dugord et al., 2014), but was associated with increased LST in Beijing, China (Li et al., 2013b; Li et al., 2012). Similarly, edge density of greenspace was found to be negatively correlated to LST in many cities (Dugord et al., 2014; Li et al., 2011; Li et al., 2014; Maimaitiyiming et al., 2014; Rhee et al., 2014; Zhang et al., 2009; Zhou et al., 2011), but positively correlated in others (Li et al., 2013b; Wu et al., 2014). This inconsistency prevents the application of results to urban greenspace planning and management (Li et al., 2013b).

The reasons for this inconsistency remain largely unaddressed. It may be because these studies have been conducted 1 ) in cities with contrasting climatic conditions; 2 ) using a variety of statistical analysis (Fan et al., 2015; Kong et al., 2014; Li et al., 2013b; Li et al., 2012; Myint et al., 2015; Zhou et al., 2011); 3) based on maps from image data with spatial resolution ranging from sub-meter to1000 $\mathrm{m}$ (Li et al., 2013b; Rhee et al., 2014; Wu et al., 2014; Zhou et al., 2011); and 4) using a variety of analytical units with different sizes such as grids or pixels (Peng et al., 2016; Rhee et al., 2014), city blocks (Dugord et al., 2014), sub-districts (Li et al., 2013b), or self-defined polygons (Zhou et al., 2011). Does spatial configuration of greenspace affect temperatures differently in cities with different climatic conditions? Or, is this inconsistency due to the varied statistical approaches applied, or different units of analysis, or different resolutions of data to map greenspace?

Here, we address these questions by conducting a comparison study of Baltimore, MD and Sacramento, CA, USA, two cities with very different climatic conditions. We quantified and compared the relationships between spatial configuration of trees and LST using different statistical approaches, and conducted the analyses at sampling units of different sizes. We mapped tree canopies using $1 \mathrm{~m}$ resolution imagery. This decision was based on the work of Li et al. (2013b), Zhou et al. (2014) and Zhou et al. (2016), which suggested that the spatial resolution of image data used to map greenspace influenced the statistical relationships between spatial configuration of greenspace and LST, and that high spatial resolution image data are more appropriate in such analysis. Results from the present study can enhance the understanding of the effects of spatial configuration of greenspace on UHI. In addition, important insights can be provided to urban planners and natural resource managers on how to mitigate the impact of urbanization on UHI through urban design and vegetation management.

\section{Methods}

\subsection{Study area}

The research focuses on two cities with contrasting climatic conditions, Baltimore, Maryland, USA, and Sacramento, California, USA. Baltimore is a temperate coastal city characterized by hot and humid summers (Brazel et al., 2000), while Sacramento has a Mediterranean climate characterized by hot, but dry summers. Baltimore is built in a biome dominated by temperate broadleaf and mixed forest, whereas Sacramento belongs to a biome dominated by grassland, with riparian forests only along the streams and shrub and woodlands that do not occur until in the sierra foothills and higher elevation (Imhoff et al., 2010).

Baltimore is the largest city in Maryland, with a total area of $239 \mathrm{~km}^{2}$ and total population of approximately 0.62 million in 2014 . Close to the Chesapeake Bay, its annual average temperature is $12.6{ }^{\circ} \mathrm{C}$, and average precipitation is approximately $1070 \mathrm{~mm}$. Sacramento is the capital city of California. It has a total area of $259 \mathrm{~km}^{2}$, and total population of about 0.48 million in 2014. Located at the confluence of the Sacramento and American rivers, its annual average temperature is $16.2^{\circ} \mathrm{C}$ and average precipitation is approximately $450 \mathrm{~mm}$. The similarity in the sizes of total population and area, but the contrast in climatic conditions and biomes, make the two cities ideal for the comparisons conducted in this research.

\subsection{Data}

\subsubsection{Land surface temperature}

The LST data were derived from the thermal infrared (TIR) band (10.40-12.50 $\mu \mathrm{m}$ ) of two Landsat-5 Thematic Mapper (TM) images with a spatial resolution of $120 \mathrm{~m}$ (Fig. $1 \mathrm{~B}_{\mathrm{LST}}, \mathrm{S}_{\mathrm{LST}}$ ). The TM data for Baltimore and Sacramento were acquired on August 11, 2007 (row 33/path 15), and August 14, 2010 (row 33/path 44), respectively. LST was derived for different years in order to coincide with the years the land cover for the two cities was collected - Baltimore in 2007 and Sacramento in 2010.

We first calculated the top-of-atmospheric (TOA) radiance based on the digital number (DN) of the TM TIR band (Chander and Markham, 2003; Landsat Project Science Office, 2009). We then calculated the surface-leaving radiance from TOA radiance by removing the effects of the atmosphere in the thermal region (Asgarian et al., 2015; Barsi et al., 2005; Sobrino et al., 2004; Yuan and Bauer, 2007; Zhou et al., 2014). Finally, LST was calculated from surface-leaving radiance using the Plank function (Chander and Markham, 2003; Chander et al., 2009).

\subsubsection{Spatial pattern of tree canopy}

We mapped the urban tree canopy based on 1-m resolution imagery from the National Agriculture Imagery Program (NAIP), using an objectbased classification approach (MacFaden et al., 2012; Zhou and Troy, 2008). The imagery is 4-band color-infrared, with radiometric depth of 8 bits. Ancillary data, such as light detecting and ranging (Lidar) data and building footprint layers, were used to aid in classification. Six classes were included in the classification map: trees (i.e., tree canopy), grasses, pavement, buildings, water and bare soil (Fig. $1 \mathrm{~B}_{\mathrm{TC}}, \mathrm{S}_{\mathrm{TC}}$ ). The accuracies of the land cover classifications were assessed by visually referencing to sub-meter high-resolution imagery using protocol developed in Zhou and Troy (2008). The overall accuracies of the classifications were $95.7 \%$ for Baltimore and $93.6 \%$ for Sacramento. The user's and producer's accuracy of trees for Baltimore were $97.3 \%$ and $97.5 \%$, and $98.2 \%$ and $96.7 \%$ for Sacramento.

There are numerous metrics that can be used to measure and describe spatial patterns of land cover features (Gustafson, 1998; McGarigal et al., 2002). Here, we chose 5 landscape metrics to measure the spatial pattern of urban trees, including one composition metric: percent cover of trees (PTree), and four configuration metrics: (1) mean patch size (AREA_MN), (2) edge density (ED), (3) mean patch shape index (SHAPE_MN), and (4) largest patch index (LPI) (Table 1). These metrics represent the primary characteristics describing the spatial pattern of trees, including the abundance of trees, size and shape of patches, edge density, and fragmentation. These metrics were chosen based on the following considerations: (1) importance in both theory and practice (Lee et al., 2009; Li and Wu, 2004; Peng et al., 2010; Zhou et al., 2011), (2) easily calculated and interpretable (Li et al., 2012; Zhou et al., 2011), and (3) minimal redundancy (Riitters et al., 1995; Li and Wu, 2004; Zhou et al., 2011). These metrics were calculated in ArcGISTM $^{\mathrm{T}} 10.1$.

\subsection{Statistics analysis}

We investigated the relationships among spatial patterns of tree canopy and LST at multiple scales, that is, using different sizes of analytical units. Specifically, 5 sizes of analytical unit were used: 1 ) $1 \times 1$ pixel 


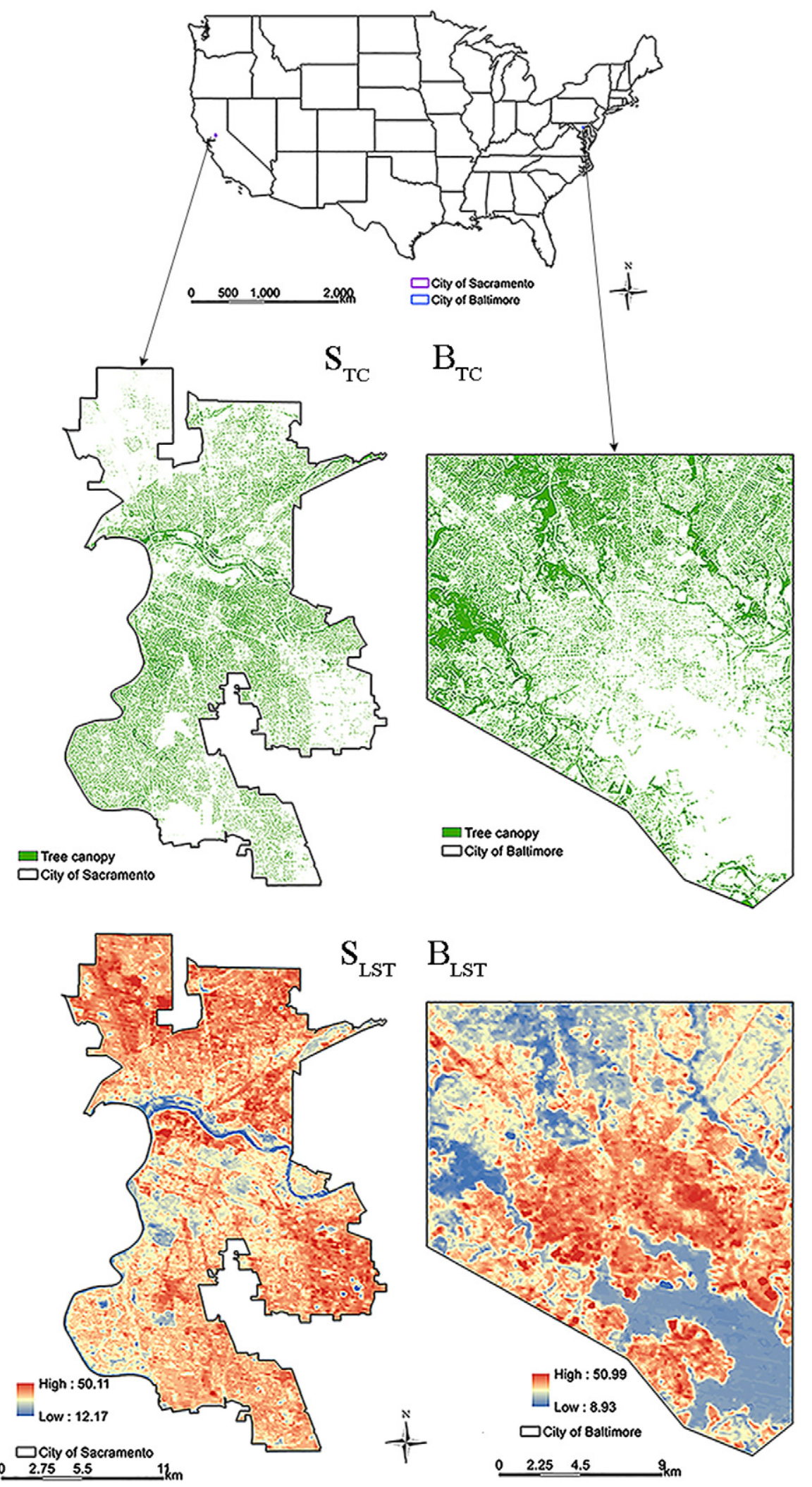

Fig. 1. The spatial distribution of tree canopy and land surface temperatures in Baltimore (panels $B_{T C}$ and $B_{L S T}$ ) and Sacramento (Panels $S_{T C}$ and $S_{L S T}$ ).

(or a grid cell of $120 \mathrm{~m} \times 120 \mathrm{~m}$, the same as the pixel size of the Landsat TM thermal band), 2) $3 \times 3$ pixels ( $360 \mathrm{~m} \times 360 \mathrm{~m}$ ), 3) $5 \times 5$ pixels $(600 \mathrm{~m} \times 600 \mathrm{~m}), 4) 7 \times 7$ pixels $(840 \mathrm{~m} \times 840 \mathrm{~m})$, and 5) $9 \times 9$ pixels $(1080 \mathrm{~m} \times 1080 \mathrm{~m})$ (Liu and Weng, 2009). For each analytical unit (i.e., a grid cell), we calculated the mean LST as the response variable for statistical analyses. The predictor variables were the percent cover of tree canopies, and the four landscape metrics (Table 1). Table A1 shows the mean and standard deviation of LST and landscape metrics.

A Pearson correlation matrix was first developed to examine the correlations between LST and the spatial pattern metrics of trees. We then 
Table 1

Landscape metrics used in this study, after McGarigal et al. (2002).

\begin{tabular}{|c|c|c|c|c|}
\hline Categories & $\begin{array}{l}\text { Landscape metrics } \\
\text { (abbreviation) }\end{array}$ & Description & $\begin{array}{l}\text { Equation } \\
\text { (unit) }\end{array}$ & Citations \\
\hline Composition & $\begin{array}{l}\text { Percent cover of tree canopy } \\
\text { (PTree) }\end{array}$ & Proportion of tree canopy area within an analysis unit. & $\frac{\sum_{i=1}^{n} a_{i}^{*}}{A} 100$ & (Li et al., 2014; Zhou et al., 2011) \\
\hline \multirow[t]{4}{*}{ Configuration } & Mean patch size (AREA_MN) & The average area of tree canopy patches within an analysis unit. & $\frac{\sum_{i=1}^{n} a_{i}}{N}$ & (Kong et al., 2014; Zhang et al., 2009) \\
\hline & $\begin{array}{l}\text { Mean patch shape index } \\
\text { (SHAPE_MN) }\end{array}$ & $\begin{array}{l}\text { The average shape index of tree canopy patches within an } \\
\text { analysis unit. }\end{array}$ & $\frac{\sum_{i=1}^{n} \frac{0.25^{*} p_{i}}{\sqrt{A}}}{N}$ & (Li et al., 2012; Peng et al., 2010) \\
\hline & Edge density (ED) & $\begin{array}{l}\text { The total perimeter of tree canopy patches per } \mathrm{km}^{2} \text { within an } \\
\text { analysis unit. }\end{array}$ & \multirow{2}{*}{$\begin{array}{l}\frac{\sum_{i=1}^{n} p_{i}{ }^{*}}{A} 10000 \\
(\mathrm{~m} / \mathrm{ha}) \\
\frac{\max a_{i} *}{A} 100 \\
(\%)\end{array}$} & $\begin{array}{l}\text { (Connors et al., 2013; Maimaitiyiming et } \\
\text { al., 2014) }\end{array}$ \\
\hline & Largest patch index (LPI) & $\begin{array}{l}\text { The proportion of the largest tree canopy patch within an } \\
\text { analysis unit. }\end{array}$ & & (Rhee et al., 2014; Zhou et al., 2011) \\
\hline
\end{tabular}

$a_{i}$ area of tree canopy patch $i$; $p_{i}$ perimeter of tree canopy patch $i$; $A$ total area of analysis unit; $N$ number of patches of tree canopy.

conducted a partial correlation analysis to investigate the relationships between LST and the configuration metrics, by controlling for the effect of the percent cover of trees. Controlling for the effect tree canopy percent is necessary because the configuration metrics were highly correlated to percent cover of trees, and therefore the Pearson correlation analysis may obtain spurious relationships between LST and configuration metrics.

We then used ordinary least squares (OLS) multiple linear regression model and spatial autoregression (SAR) model to examine the effects of the spatial pattern of trees on LST. We used standardized coefficients (beta weights) to evaluate the relative importance of percent cover and configuration metrics on predicting LST (Weng et al., 2006; Yan et al., 2014; Zhou et al., 2011), and variance partitioning to quantify the explanatory power of the predictors (Anderson and Gribble, 1998; Li et al., 2013a; Li et al., 2012).

The OLS regression model is the most commonly used statistical analysis, with the assumption that the error terms are independent. The primary analyses showed that significant spatial autocorrelation $(P<0.01)$ occurred in the residuals of the OLS model. Consequently, spatial autoregression models that integrate spatial autocorrelation into modeling were more appropriate to investigate the relationships between LST and spatial patterns of trees (Li et al., 2012). We also included the OLS regression model for comparison purposes, as many studies in the literature use such analyses. Below, we briefly describe the spatial autoregression models and variance partitioning. More details can be found in Li et al. (2012).

With SAR, the neighborhood relationship of the response variable is explicitly measured by a ( $\mathrm{n} \times \mathrm{n})$ matrix of spatial weights, which is integrated into the standard multiple linear regression to account for spatial autocorrelation (Anselin, 2005a). The spatial autocorrelation can be modeled in two ways: a spatial lag model and a spatial error model (Anselin, 2005a). The spatial lag model assumes that the spatial autoregressive occurs only in the response variable. The form of the spatial lag model is:

$\mathrm{y}=\rho \mathrm{Wy}+\beta \mathrm{X}+\varepsilon$

where Wy is a $(n \times 1)$ vector of the spatially lagged response variable, $\rho$ is a spatial autoregressive coefficient, $\mathrm{X}$ is a ( $\mathrm{n} \mathrm{x} \mathrm{k}$ ) vector of explanatory variables, $\beta$ is a $(k \times 1)$ vector of regression coefficients, and $\varepsilon$ is a $(n \times 1)$ vector of independently distributed errors.

In contrast, the spatial error model assumes the spatial effects that are not fully explained by the explanatory variables occurs in the error terms, and therefore, is expressed as:

$\mathrm{y}=\beta \mathrm{X}+\lambda \mathrm{W} \mu+\varepsilon$

where $W \mu$ is a $(n \times 1)$ vector of spatially lagged errors, and $\lambda$ is a spatial autoregressive coefficient.
We used the Lagrange Multiplier statistics to compare the two modeling approaches, and found that the spatial error model better fit the data in this study. The regressions were then run using the spatial error model, and a maximum likelihood method. The $\mathrm{R}^{2}$ values were calculated as detailed in Lichstein et al. (2002), which were comparable with those from the OLS regression model. The regressions were run in GeoDa 1.6.7 and spdep package of R (Version 2.12.1; R Development Core Team, 2011).

Variance partitioning was used to quantify the relative variations in LST explained by: the percent cover of trees and the configuration metrics. The variation of LST was divided into four fractions: (1) unique effects of percent cover of trees, (2) unique effects of configuration metrics, (3) joint effects of percent cover of trees and configuration metrics, and (4) unexplained. Variance partitioning was conducted following the procedure detailed in Anderson and Gribble (1998) and in Heikkinen et al. (2005), using the spdep package (Anselin, 2005b) of $R$ (Version 2.12.1; R. Team, 2011).

\section{Results}

\subsection{The spatial distribution of trees and LST in the two cities}

The percent cover of trees, as well as the spatial configuration, differed greatly between the two cities (Fig. $1 \mathrm{~B}_{\mathrm{TC}}, \mathrm{S}_{\mathrm{TC}}$ ). Approximately $27.1 \%$ of the land in Baltimore was covered by trees, but only $16.7 \%$ in Sacramento. Compared to Sacramento, trees in Baltimore are more clustered, especially in the northwest region of the city (Fig. 1 B $\mathrm{BC}_{\mathrm{TC}}$ ). For both cities, percent cover of trees varied greatly in space. Taking the analytical unit of $600 \times 600 \mathrm{~m}$ as an example, percent cover of trees in grid cells varied from $0.50 \%$ to $92.62 \%$ across Baltimore, with a standard deviation of $18.73 \%$. In Sacramento, percent cover ranged from 0 to $58.68 \%$, with a standard deviation of $12.12 \%$ (Table A1). The mean patch size of trees in Baltimore was $599.6 \mathrm{~m}^{2}$, much greater than that of $73.80 \mathrm{~m}^{2}$ in Sacramento. In contrast, the patch density and edge density of trees in Sacramento were much higher than that of Baltimore (2227/ $\mathrm{km}^{2}$ versus 399/ $\mathrm{km}^{2}$ for patch density and $819.85 \mathrm{~m} /$ ha versus $422.31 \mathrm{~m} /$ ha for edge density), suggesting that tree cover was more fragmented in Sacramento. The mean shape index was similar in the two cities (1.32 in Baltimore and 1.39 in Sacramento), suggesting that the complexity of the tree patches is similar.

Land surface temperatures varied greatly in space for both cities (Fig. $1 \mathrm{~S}_{\mathrm{LST}}, \mathrm{S}_{\mathrm{LST}}$ ). LST in Baltimore ranged from $8.93{ }^{\circ} \mathrm{C}$ to $50.99{ }^{\circ} \mathrm{C}$, with a mean of $33.37^{\circ} \mathrm{C}$ and standard deviation of $4.69{ }^{\circ} \mathrm{C}$, while it ranged from $12.17{ }^{\circ} \mathrm{C}$ to $50.11^{\circ} \mathrm{C}$, with a mean of $35.60{ }^{\circ} \mathrm{C}$ and standard deviation of $3.25^{\circ} \mathrm{C}$ in Sacramento (Table A1). For both cities, LST was significantly autocorrelated in space, as indicated by Moran's I (Baltimore: Moran's $I=0.88, p<0.01$; Sacramento: Moran's $I=0.72, p<$ $0.01)$. LST tended to be higher in locations with less tree canopy coverage (Fig. $1 \mathrm{~B}_{\mathrm{TC}}, \mathrm{B}_{\mathrm{TC}}, \mathrm{S}_{\mathrm{LST}}, \mathrm{S}_{\mathrm{LST}}$ ). 
3.2. Effect of spatial patterns of trees on LST: difference between cities and across analytical scales

\subsubsection{Effects of percent cover of trees on LST}

The percent cover of trees was significantly negatively correlated with LST, across all analytical scales, for both cities, suggesting LST decreased with the increase of percent cover of trees (Table 2; Fig. A1). The Pearson correlation analysis showed that percent cover of tree canopy had the strongest correlation with LST among the 5 metrics. For both cities, the strength of the correlations between LST and percent cover of trees, as indicated by the correlation coefficients, increased with the increase of the size of the analytical unit. The correlations between LST and percent cover of trees, however, were generally stronger in Baltimore than in Sacramento across all 5 analytical scales, suggesting that percent cover of trees might explain more variations of LST in milder coastal regions compared to hotter and drier ones.

\subsubsection{Effects of spatial configuration of trees on LST}

The Pearson correlation analysis showed that all 4 metrics of tree configuration were significantly, negatively correlated with LST, across all analytical scales, for both cities (Table 2). Similar to percent cover of trees, the strength of the correlations between LST and the 4 configuration metrics also generally increased with the increase of the size of the analytical unit; the correlations between LST and the 4 configuration metrics were stronger in Baltimore than in Sacramento. Among the 4 configuration metrics, the largest patch index had relatively strong correlations with LST.

After controlling for the effects of percent cover of trees, the correlations (i.e., partial correlations) between configuration metrics and LST changed greatly, as indicated by the results from the partial correlation analysis (Table 2). These changes included the following: 1) the strength of partial correlations, measured by the partial correlation coefficients, greatly decreased, compared with their corresponding Pearson correlation coefficients; 2) some of the configuration metrics were no longer significantly correlated to LST; and 3) more notably, the relationships between some of the configuration metrics and LST changed from negative to positive.

These changes in the relationships between LST and configuration metrics, however, varied dramatically in the two cities, in terms of magnitude, significance, and direction. Specifically, after controlling for the

Table 2

Correlation coefficients between LST and landscape metrics. The italic and bold rows are for partial correlation analysis, where for configuration metrics, the control variable was percent cover of tree, and for percent cover of tree, the control variables were the configuration metrics.

\begin{tabular}{|c|c|c|c|c|c|c|}
\hline City & Scale & PTree & AREA_MN & SHAPE_MN & ED & LPI \\
\hline \multirow[t]{10}{*}{ Baltimore } & \multirow[t]{2}{*}{$120 \mathrm{~m}$} & $-0.830^{* *}$ & $-0.561^{* *}$ & $-0.418^{* *}$ & $-0.559^{* *}$ & $-0.782^{* *}$ \\
\hline & & $-0.260^{* *}$ & $0.054^{* *}$ & 0.003 & $-0.033^{* *}$ & $0.036^{* *}$ \\
\hline & \multirow[t]{2}{*}{$360 \mathrm{~m}$} & $-0.904^{* *}$ & $-0.453^{* *}$ & $-0.604^{* *}$ & $-0.555^{* *}$ & $-0.805^{* *}$ \\
\hline & & $-0.502^{* *}$ & $0.059^{*}$ & $-0.143^{* *}$ & -0.007 & $0.076^{* *}$ \\
\hline & \multirow[t]{2}{*}{$600 \mathrm{~m}$} & $-0.926^{* *}$ & $-0.478^{* *}$ & $-0.752^{* *}$ & $-0.578^{* *}$ & $-0.796^{* *}$ \\
\hline & & $-0.499^{* *}$ & 0.085 & $-0.308^{* *}$ & -0.011 & $0.123^{* *}$ \\
\hline & \multirow[t]{2}{*}{$840 \mathrm{~m}$} & $-0.937^{* *}$ & $-0.687^{* *}$ & $-0.764^{* *}$ & $-0.604^{* *}$ & $-0.779^{* *}$ \\
\hline & & $-0.574^{* *}$ & 0.119 & $-0.363^{* *}$ & -0.053 & $0.185^{* *}$ \\
\hline & \multirow{2}{*}{$\begin{array}{l}1080 \\
\mathrm{~m}\end{array}$} & $-0.948^{* *}$ & $-0.535^{* *}$ & $-0.767^{* *}$ & $-0.618^{* *}$ & $-0.778^{* *}$ \\
\hline & & $-0.562^{* *}$ & 0.149 & $-0.390^{* *}$ & -0.116 & $0.224^{*}$ \\
\hline \multirow[t]{10}{*}{ Sacramento } & \multirow[t]{2}{*}{$120 \mathrm{~m}$} & $-0.640^{* *}$ & $-0.354^{* *}$ & $-0.361^{* *}$ & $-0.464^{* *}$ & $-0.602^{* *}$ \\
\hline & & $-0.234^{* *}$ & $-0.147^{* *}$ & $-0.115^{* *}$ & $0.197^{* *}$ & $-0.157^{* *}$ \\
\hline & \multirow[t]{2}{*}{$360 \mathrm{~m}$} & $-0.723^{* *}$ & $-0.704^{* *}$ & $-0.332^{* *}$ & $-0.525^{* *}$ & $-0.611^{* *}$ \\
\hline & & $-0.134^{* *}$ & $-0.432^{* *}$ & $-0.051^{*}$ & $0.309^{* *}$ & $-0.219^{* *}$ \\
\hline & \multirow[t]{2}{*}{$600 \mathrm{~m}$} & $-0.768^{* *}$ & $-0.750^{* *}$ & $-0.345^{* *}$ & $-0.564^{* *}$ & $-0.588^{* *}$ \\
\hline & & $-0.087^{*}$ & $-0.475^{* *}$ & 0.041 & $0.341^{* *}$ & $-0.238^{* *}$ \\
\hline & \multirow[t]{2}{*}{$840 \mathrm{~m}$} & $-0.811^{* *}$ & $-0.788^{* *}$ & $-0.545^{* *}$ & $-0.609^{* *}$ & $-0.609^{* *}$ \\
\hline & & -0.105 & $-0.529^{* *}$ & 0.025 & $0.375^{* *}$ & $-0.253^{* *}$ \\
\hline & 1080 & $-0.819^{* *}$ & $-0.822^{* *}$ & $-0.578^{* *}$ & $-0.610^{* *}$ & $-0.589^{* *}$ \\
\hline & $\mathrm{m}$ & 0.047 & $-0.565^{* *}$ & -0.022 & $0.410^{* *}$ & $-0.259^{* *}$ \\
\hline
\end{tabular}

\footnotetext{
** $P<0.01$.
}

* $P<0.05$ (2-tailed) effects of percent cover of trees, the correlation between mean patch size (AREA_MN) and LST changed from negative to positive when the analytical unit was less than or equal to $360 \mathrm{~m}$, and then to no longer significant in Baltimore. Similarly, edge density (ED) was no longer significantly correlated to LST at the analytical unit $>120 \mathrm{~m}$ on a side. In Sacramento, however, AREA_MN still had a relatively strong negative relationship with LST across all scales, but the relationships between ED and LST changed from negative to positive. SHAPE_MN remained significantly correlated with LST in Baltimore, but not in Sacramento. LPI remained significantly correlated with LST for both cities. However, these correlations changed from negative to positive in Baltimore, when controlling for the effects of percent cover of trees (Table 2). For all 4 configuration metrics, the partial correlations were stronger in Sacramento than in Baltimore, in contrast to the Pearson correlations.

\subsubsection{Relative importance of amount and configuration of trees on LST}

Results from the OLS multiple linear regressions showed that in Baltimore, percent cover of trees (PTree) had significantly negative effects on LST, across the 5 analytical scales (Table 3 ). In addition, PTree was the most important predictor of LST, playing a much more important role in predicting LST than the other spatial configuration variables, as suggested by the standard coefficients (Table 3 ). None of the configuration variables were significant at any analytical scale. Among the 4 configuration metrics, shape index (SHAPE_MN) played a relatively important role in predicting LST, and had a negative effect (Table 3). Results from the variation partitioning also indicated that percent cover of trees played a more important role than that of configuration of trees (Fig. 2).

In Sacramento, however, the relative importance of percent cover of trees (PTree) and spatial configuration differed greatly from that of Baltimore. PTree became no longer significantly related to LST at the analytical units having length scales of $840 \mathrm{~m}$ and $1080 \mathrm{~m}$. In contrast, mean patch size (AREA_MN) was significant at all 5 analytical units, and shape index (SHAPE_MN) and edge density (ED) were significant at all scales except for $360 \mathrm{~m}$. In addition, configuration metrics became more important in predicting LST, with AREA_MN being the most important predictor of LST for analytical units larger than $120 \mathrm{~m}$ on a side (Table 3). Results from the variation partitioning also indicated that configuration of trees played a more important role than that of percent cover of trees (Fig. 2).

Overall, results from the spatial error models were similar to those of the OLS regression models (Table 4). This was particularly true when the analytical units were relatively large. For example, when the analytical unit was greater than or equal to $600 \mathrm{~m}$ on a side, the coefficients of the predictors, and the $\mathrm{R}^{2}$ values were similar between OLS models and spatial error models. However, it should be noted that at the analytical length scale of $120 \mathrm{~m}$, the absolute values of coefficients from the spatial error models were much smaller than those from the OLS regression models, suggesting the importance of considering spatial autocorrelation at finer scales.

For both OLS and SAR, results from the standard coefficients and variance partitioning showed that among the five metrics, PTree was the most important predictor of LST in Baltimore. In Sacramento, however, configuration metrics, such as AREA_MN, were better predictors of LST than PTree, when the size of analytical unit was $>120 \mathrm{~m}$ (for OLS) or $360 \mathrm{~m}$ (for SAR).

\section{Discussion}

\subsection{The effects of tree cover and its spatial configuration on LST: relative im-} portance varied greatly between cities in different climatic zones

Percent cover of trees had similar effects on LST for both cities despite the different climatic conditions of these cities. These results are similar to findings from previous studies (Li et al., 2011; Li et al., 2013b; Weng et al., 2004; Zhou et al., 2011). Increasing the percent cover of trees can significantly decrease LST for both cities. However, the efficiency in cooling, defined as the decrease in degrees of LST 
Table 3

Results from the OLS multiple linear regressions and the diagnostics for spatial dependence. The bold and italic rows are standardized coefficients.

\begin{tabular}{|c|c|c|c|c|c|c|c|c|c|}
\hline City & Scale & PTree & AREA_MN & SHAPE_MN & ED & LPI & $\mathrm{R}^{2}$ & Moran's I & AIC \\
\hline \multirow[t]{10}{*}{ Baltimore } & \multirow[t]{2}{*}{$120 \mathrm{~m}$} & $-0.154^{* *}$ & $7.879 \mathrm{E}-05^{* *}$ & 0.024 & $1.772 \mathrm{E}-06$ & 0.007 & \multirow[t]{2}{*}{0.690} & \multirow[t]{2}{*}{0.602} & \multirow[t]{2}{*}{$63,539.400$} \\
\hline & & -0.911 & 0.043 & 0.002 & 0.014 & 0.042 & & & \\
\hline & \multirow[t]{2}{*}{$360 \mathrm{~m}$} & $-0.195^{* *}$ & $5.860 \mathrm{E}-05^{* *}$ & $-2.071^{* *}$ & $1.359 \mathrm{E}-05^{* *}$ & $0.024^{* *}$ & \multirow[t]{2}{*}{0.824} & \multirow[t]{2}{*}{0.460} & \multirow[t]{2}{*}{5478.030} \\
\hline & & -1.046 & 0.060 & -0.091 & 0.085 & 0.126 & & & \\
\hline & \multirow[t]{2}{*}{$600 \mathrm{~m}$} & $-0.168^{* *}$ & $1.291 \mathrm{E}-04^{* *}$ & $-8.697^{* *}$ & $1.225 \mathrm{E}-05^{*}$ & 0.001 & \multirow[t]{2}{*}{0.877} & \multirow[t]{2}{*}{0.427} & \multirow[t]{2}{*}{1619.540} \\
\hline & & -0.883 & 0.099 & -0.203 & 0.073 & 0.005 & & & \\
\hline & \multirow[t]{2}{*}{$840 \mathrm{~m}$} & $-0.179^{* *}$ & $2.168 \mathrm{E}-04$ & $-10.290^{* *}$ & $1.692 \mathrm{E}-05^{*}$ & 0.003 & \multirow[t]{2}{*}{0.897} & \multirow[t]{2}{*}{0.372} & \multirow[t]{2}{*}{708.088} \\
\hline & & -0.934 & 0.088 & -0.202 & 0.097 & 0.017 & & & \\
\hline & \multirow[t]{2}{*}{$1080 \mathrm{~m}$} & $-0.168^{* *}$ & $1.080 \mathrm{E}-04$ & $-11.524^{* *}$ & $9.709 \mathrm{E}-06$ & -0.003 & \multirow[t]{2}{*}{0.915} & \multirow[t]{2}{*}{0.424} & \multirow[t]{2}{*}{365.764} \\
\hline & & -0.865 & 0.064 & -0.199 & 0.054 & -0.014 & & & \\
\hline \multirow[t]{10}{*}{ Sacramento } & \multirow[t]{2}{*}{$120 \mathrm{~m}$} & $-0.160^{* *}$ & $-0.001^{* *}$ & $-0.993^{* *}$ & $1.435 \mathrm{E}-05^{* *}$ & -0.002 & \multirow[t]{2}{*}{0.449} & \multirow[t]{2}{*}{0.653} & \multirow[t]{2}{*}{$75,885.800$} \\
\hline & & -0.817 & -0.039 & -0.138 & 0.304 & -0.006 & & & \\
\hline & \multirow[t]{2}{*}{$360 \mathrm{~m}$} & $-0.083^{* *}$ & $-0.014^{* *}$ & 0.309 & $-1.991 \mathrm{E}-06$ & 0.008 & \multirow[t]{2}{*}{0.612} & \multirow[t]{2}{*}{0.393} & \multirow[t]{2}{*}{6578.530} \\
\hline & & -0.419 & -0.434 & 0.018 & -0.041 & 0.019 & & & \\
\hline & \multirow[t]{2}{*}{$600 \mathrm{~m}$} & $-0.047^{*}$ & $-0.019^{* *}$ & $3.649^{* *}$ & $-1.137 \mathrm{E}-05^{* *}$ & 0.016 & \multirow[t]{2}{*}{0.696} & \multirow[t]{2}{*}{0.323} & \multirow[t]{2}{*}{1973.260} \\
\hline & & -0.245 & -0.596 & 0.142 & -0.231 & 0.033 & & & \\
\hline & $840 \mathrm{~m}$ & -0.051 & $-0.023^{* *}$ & $7.498^{* *}$ & $-1.450 \mathrm{E}-05^{*}$ & $0.068^{*}$ & 0.770 & 0.369 & 823.595 \\
\hline & & -0.266 & -0.700 & 0.203 & -0.298 & 0.114 & & & \\
\hline & $1080 \mathrm{~m}$ & 0.025 & $-0.032^{* *}$ & $8.182^{* *}$ & $-2.671 \mathrm{E}-05^{* *}$ & 0.028 & 0.796 & 0.318 & 413.287 \\
\hline & & 0.131 & -0.876 & 0.212 & -0.546 & 0.046 & & & \\
\hline
\end{tabular}

** $P<0.01$

* $P<0.05$ (2-tailed).

with every $1 \%$ increase in tree cover (Buyantuyev and Wu, 2010; Hamada and Ohta, 2010; Li et al., 2013b; Peng et al., 2016; Xie et al., 2013), was higher in Baltimore than in Sacramento at all five scales of analytical unit (Table 5). The results remained the same even after considering the effects of spatial configuration, except for the analysis at the scale of $120 \mathrm{~m}$ (Tables 3 \& 4). These results contrast with previous work conducted within southern California that showed more effective cooling by vegetation in hotter and drier desert regions compared to milder coastal ones (Tayyebi and Darrel Jenerette, 2016). However, it should be noted that Tayyebi and Darrel Jenerette (2016) used the normalized difference vegetation index (NDVI) to measure the abundance of vegetation, which includes both trees and grass/lawns. But here we used the percent cover of trees. Previous findings have shown that grass is less effective than tree canopy for LST cooling (Myint et al.,

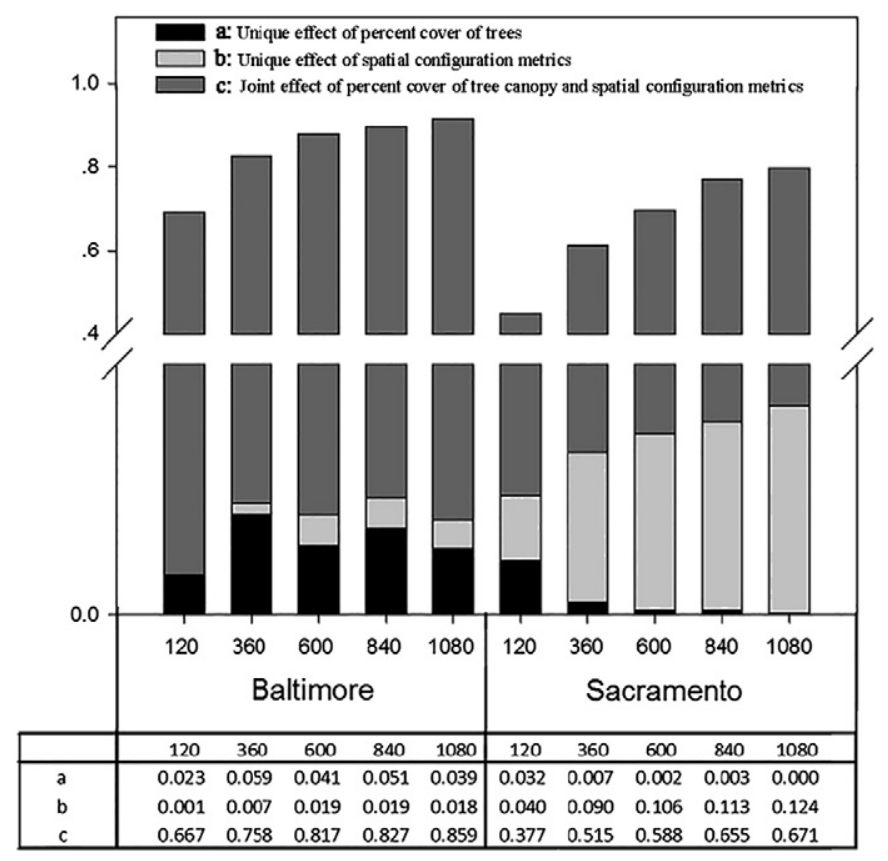

Fig. 2. The results of variance partitioning for percent cover of tree canopy and spatial configuration across spatial scales.
2015), and its cooling effectiveness is likely to be more affected by different management practices such as irrigation.

The cooling efficiency of urban trees can be affected by many factors such as tree species, spatial configuration of trees, and management practices because, for example, transpiration rates of urban trees vary greatly by species (Pataki et al., 2011; Wang et al., 2011), and are affected by climatic factors such as air temperature, total radiation, vapor pressure deficit, and ambient pollutants such as ozone (Wang et al., 2011). These contrasting results warrant further research on the cooling effectiveness of vegetation/trees that requires field work on species identity, species transpiration rates, vegetation management such as irrigation, and more detailed climate records (McCarthy et al., 2011; Pataki et al., 2011; Polsky et al., 2014; Zhou et al., 2008).

Effects of spatial configuration of tree cover on LST, however, varied greatly in the two cities, in terms of magnitude, significance, and even direction of effect. Some configuration metrics had contradictory effects on LST between the two cities. For example, after controlling for the effects of percent cover of trees, mean patch size was positively correlated to LST in Baltimore, but was negatively correlated in Sacramento. Because larger patches have lower edge densities (Table A2), it follows that edge density was negatively correlated to LST in Baltimore, but was positively correlated in Sacramento. Previous studies on different cities have also found contradictory results of spatial configuration of greenspace/tree canopy on LST. For example, edge density of vegetation cover was found to be negatively correlated with LST in Baltimore (Zhou et al., 2011), Shanghai (Li et al., 2011; Li et al., 2014), and Berlin (Dugord et al., 2014), but positive in Beijing (Li et al., 2013b). Our results from the comparison of the two cities indicated that the spatial configuration of trees may have different effects on LST in cities with different climatic conditions. These results enhance the understanding of the inconsistency of effects of spatial configuration of trees/greenspace on LST from previous studies.

Trees ameliorate temperatures primarily in two ways: providing shade and through evapotranspiration. The contradictory results of configuration metrics found in the two cities may be due to differences in the relative contributions of the two cooling processes and these differences may be related to different climatic conditions between the cities. Here, we again take edge density as an example. Increasing total edges and edge density may potentially lead to an increase of shade provided by trees to surrounding surfaces (Li et al., 2012; Zhou et al., 2011). In addition, greater total edges and edge density may also enhance energy flow and exchange between trees and their surrounding areas 
Table 4

The results of spatial error models. The bold and italic rows are standardized coefficients.

\begin{tabular}{|c|c|c|c|c|c|c|c|c|}
\hline City & Scale & PTree & AREA_MN & SHAPE_MN & ED & LPI & $\mathrm{R}^{\wedge} 2$ & AIC \\
\hline \multirow[t]{10}{*}{ Baltimore } & \multirow[t]{2}{*}{$120 \mathrm{~m}$} & $-0.059^{* *}$ & $9.370 \mathrm{E}-06$ & $-0.122^{* *}$ & $-1.376 \mathrm{E}-06$ & $0.004^{* *}$ & \multirow[t]{2}{*}{0.932} & \multirow[t]{2}{*}{$42,232.200$} \\
\hline & & -0.349 & 0.005 & -0.012 & -0.011 & 0.026 & & \\
\hline & \multirow[t]{2}{*}{$360 \mathrm{~m}$} & $-0.148^{* *}$ & $2.432 \mathrm{E}-05^{*}$ & $-0.997^{* *}$ & $1.072 \mathrm{E}-05^{* *}$ & 0.010 & \multirow[t]{2}{*}{0.900} & \multirow[t]{2}{*}{4663.350} \\
\hline & & -0.790 & 0.025 & -0.044 & 0.067 & 0.052 & & \\
\hline & \multirow[t]{2}{*}{$600 \mathrm{~m}$} & $-0.171^{* *}$ & $7.819 \mathrm{E}-05^{* *}$ & $-5.565^{* *}$ & $2.306 \mathrm{E}-05^{* *}$ & 0.010 & \multirow[t]{2}{*}{0.920} & \multirow[t]{2}{*}{1405.970} \\
\hline & & -0.900 & 0.060 & -0.130 & 0.137 & 0.048 & & \\
\hline & \multirow[t]{2}{*}{$840 \mathrm{~m}$} & $-0.165^{* *}$ & $8.307 \mathrm{E}-05$ & $-10.560^{* *}$ & $2.135 \mathrm{E}-05^{* *}$ & 0.001 & \multirow[t]{2}{*}{0.924} & \multirow[t]{2}{*}{641.347} \\
\hline & & -0.858 & 0.034 & -0.207 & 0.123 & 0.004 & & \\
\hline & \multirow[t]{2}{*}{$1080 \mathrm{~m}$} & $-0.164^{* *}$ & $5.917 \mathrm{E}-05$ & $-11.100^{* *}$ & $1.735 \mathrm{E}-05^{* *}$ & -0.003 & \multirow[t]{2}{*}{0.941} & \multirow[t]{2}{*}{317.275} \\
\hline & & -0.846 & 0.035 & -0.191 & 0.097 & -0.013 & & \\
\hline \multirow[t]{10}{*}{ Sacramento } & \multirow[t]{2}{*}{$120 \mathrm{~m}$} & $-0.063^{* *}$ & 0.000 & $-0.251^{* *}$ & $5.363 \mathrm{E}-06^{* *}$ & 0.003 & \multirow[t]{2}{*}{0.865} & \multirow[t]{2}{*}{$51,781.6$} \\
\hline & & -0.319 & 0.001 & -0.035 & 0.114 & 0.011 & & \\
\hline & \multirow[t]{2}{*}{$360 \mathrm{~m}$} & $-0.114^{* *}$ & $-0.007^{* *}$ & -0.218 & $5.921 \mathrm{E}-06^{*}$ & 0.015 & \multirow[t]{2}{*}{0.741} & \multirow[t]{2}{*}{5875.27} \\
\hline & & -0.572 & -0.211 & -0.013 & 0.120 & 0.035 & & \\
\hline & \multirow[t]{2}{*}{$600 \mathrm{~m}$} & $-0.047^{*}$ & $-0.015^{* *}$ & $2.631^{* *}$ & $-8.548 \mathrm{E}-06$ & 0.001 & \multirow[t]{2}{*}{0.763} & \multirow[t]{2}{*}{1827.85} \\
\hline & & -0.243 & -0.480 & 0.102 & -0.173 & 0.002 & & \\
\hline & \multirow[t]{2}{*}{$840 \mathrm{~m}$} & $-0.072^{*}$ & $-0.021^{* *}$ & $7.121^{* *}$ & $-8.109 \mathrm{E}-06$ & $0.061^{*}$ & \multirow[t]{2}{*}{0.827} & \multirow[t]{2}{*}{744.035} \\
\hline & & -0.379 & -0.637 & 0.193 & -0.167 & 0.102 & & \\
\hline & \multirow[t]{2}{*}{$1080 \mathrm{~m}$} & 0.019 & $-0.034^{* *}$ & $8.371^{* *}$ & $-2.298 \mathrm{E}-05^{* *}$ & 0.029 & \multirow[t]{2}{*}{0.838} & \multirow[t]{2}{*}{379.032} \\
\hline & & 0.101 & -0.932 & 0.217 & -0.469 & 0.048 & & \\
\hline
\end{tabular}

** $P<0.01$.

* $P<0.05$ (2-tailed).

(Cadenasso et al., 2003; Zhou et al., 2011). Consequently, considering only the shading process, increasing edge density will lead to lower LST. However, increased edge density is frequently a result of more fragmented tree cover, given a fixed amount of total tree coverage. As large and continuous tree stands generally have lower temperature than that of fragmented and smaller patches (Cao et al., 2010; Yokohari et al., 1997; Zhang et al., 2009), suggesting stronger evapotranspiration efficiency of larger patches, increasing edge density is likely to reduce evapotranspiration efficiency. This is particularly predominant in cities such as Sacramento that have very dry and hot summers, during which vegetation is very likely to experience water and temperature stress (Connors et al., 2013; Maimaitiyiming et al., 2014). This is because the ambient temperature and humidity affect the transpiration rate of trees in a non-linear (an inverted $U$ shape) way (Lambers et al., 2008; Schulze et al., 2005). That is, while increasing temperature and reducing humidity to some extent can induce the stomata open and thus enhance transpiration, excessive heat and increasing vapor pressure deficit between leaf and air will lead to dramatic reduction in transpiration (Lambers et al., 2008; Schulze et al., 2005). Therefore, whether the increase of edge density will lead to a decrease or increase in LST will largely depend on the net effects of increased shading effects and reduced evapotranspiration effects. In Mediterranean climate cities such as Sacramento, the reduction in evapotranspiration caused by increased edge density is likely to outweigh increased shading. Consequently, edge density has a positive relationship with LST, given a fixed amount of tree coverage. But this is the opposite in cities such as Baltimore that experience a relative humid summer.

Similar to edge density, whether the increase of mean patch size leads to a decrease or increase in LST largely depends on the joint effects of the two key cooling processes, shading and evapotranspiration of trees. In contrast to edge density, an increase in mean patch size will likely result in increased evapotranspiration efficiency (Cao et al.,

Table 5

Results from OLS linear regression. The response variable, LST, was predicted by PTree.

\begin{tabular}{llllll}
\hline \multirow{2}{*}{ Scale } & \multicolumn{2}{l}{ Baltimore } & & & \multicolumn{2}{l}{ Sacramento } \\
\cline { 2 - 3 } \cline { 5 - 6 } & Coef. & $\mathrm{R}^{2}$ & & Coef. & $\mathrm{R}^{2}$ \\
\hline $120 \mathrm{~m}$ & -0.144 & 0.689 & & -0.129 & 0.409 \\
$360 \mathrm{~m}$ & -0.173 & 0.817 & & -0.147 & 0.523 \\
$600 \mathrm{~m}$ & -0.18 & 0.858 & & -0.152 & 0.59 \\
$840 \mathrm{~m}$ & -0.184 & 0.877 & & -0.158 & 0.657 \\
$1080 \mathrm{~m}$ & -0.188 & 0.898 & & -0.16 & 0.671 \\
\hline
\end{tabular}

2010; Yokohari et al., 1997; Zhang et al., 2009), but reduced shading effects. An increase in mean patch size will likely lead to reduced shading effects because given a fixed amount of tree cover, an increase in mean patch size leads to a decrease in edge density (Table A2), which results in reduced shading effects, as discussed above. In the hotter and drier Sacramento area, the increased evapotranspiration caused by increased mean patch size is likely to outweigh reduction in shading. Therefore, mean patch size has a negative relationship with LST, given a fixed amount of tree coverage. In Baltimore, however, reduction in shading outweighed increased evapotranspiration, and thus an increase in mean patch size led to higher LST.

Notably, the relative importance of mean patch size in predicting LST increased with the increased size of analytical unit in Sacramento, but the opposite was found in Baltimore, both suggesting clear scale effects. These scale effects may suggest that the two cooling processes, shading and evapotranspiration of trees, and their relative importance, change with scale, and differ by cities with different climatic conditions. This hypothesis, however, warrants further research.

The relative importance of percent cover of trees, and spatial configuration on LST also varied greatly between the two cities. Percent cover of trees was the most important variable in predicting LST in Baltimore. This is consistent with many of the previous studies that have found that percent cover of trees (or greenspaces) plays a more important role than their spatial configuration (Li et al., 2012; Xie et al., 2013; Zhou et al., 2011). However, spatial configuration of tree cover, such as the mean patch size, played a more important role in predicting LST than the percent cover of trees in Sacramento. In fact, the importance of percent cover of trees in predicting LST decreased with the increase of the size of analytical unit, and even became insignificant at the size of $840 \mathrm{~m}$ and greater (Table 3 ). This result is similar to the findings of Maimaitiyiming et al. (2014) in a study conducted in Aksu, Xinjiang, China, and of Li et al. (2016) in a study of Phoenix, Arizona, USA. Both cities are relatively dry and hot in summer, similar to Sacramento. These results indicated that the relative importance of percent cover of trees and their spatial configuration may vary by cities with different climatic conditions. It should be noted, however, that at the finest scale in this study - analytical unit of $120 \mathrm{~m}$ - percent cover of trees was a much better predictor of LST than any configuration metrics in Sacramento (Table 3 ). With the recent availability of very fine resolution LST data ( $7 \mathrm{~m}$ resolution, e.g., Jenerette et al., 2016), research on how the relationship between spatial pattern of trees and LST varies by unit of analysis at a scale finer than $120 \mathrm{~m}$ would be highly desirable to expand our understanding of the scale effects. 
4.2. The methodological implications: it is crucially important to choose the appropriate statistical approaches

Our results underscore the necessity of controlling for the effects of percent cover of trees when quantifying the effects of spatial configuration of tree cover on LST. For both cities, after controlling for the effects of percent cover of trees (either through partial correlation or linear regression modeling), the relationships between LST and configuration metrics dramatically changed, compared with results from the Pearson correlation analysis. For example, the relationship between LST and mean patch size (AREA_MN) changed from negative to positive in Baltimore. Similarly, the relationship between LST and edge density (ED) in Sacramento changed from negative to positive. This is because most of the configuration variables are inherently correlated to percent cover of trees (Tables A3 \& A4; Li and Wu, 2004; Peng et al., 2010; Riitters et al., 1995). For example, mean patch size had a significantly negative correlation with LST based on the Pearson correlation analysis $(r=-0.56, P<0.01$; Table 2$)$ in Baltimore at the scale of $120 \mathrm{~m}$. This observed correlation, however, is due to the very strong positive correlation between mean patch size and percent cover of trees $(r=0.70, P<$ 0.01 ; Table A3). After controlling for the effect of percent cover of trees, mean patch size in fact had a significantly positive correlation with LST, due to the reasons we discussed in Section 4.1. Therefore, it is crucially important to use statistical methods such as partial correlation and multiple regression models, instead of Pearson correlation, to assess the relative contributions of percent cover of trees and configuration to LST. Using Pearson correlation analysis may generate misleading results.

Other statistical approaches, such as path analysis and structural equation modeling have been increasingly used to identify the complex and nested relationships among social conditions, land cover and surface temperatures (Jenerette et al., 2007; Huang and Cadenasso, 2016; Tayyebi and Darrel Jenerette, 2016), which potentially allow the evaluation of direct and indirect effects of tree cover and configuration on LST.

Our results also showed that the spatial autocorrelation could influence the relationships between landscape metrics and LST. This is particularly true when the unit of analysis is relatively small. However, when the unit of analysis in this study is relatively large (i.e., equal to or greater than a linear dimension of $600 \mathrm{~m}$ ), results from OLS modeling and SAR modeling were similar, in terms of both regression coefficient and $\mathrm{R}^{2}$. This may suggest that the frequently used OLS is appropriate at such scales.

We found that with increasing size of the analytical unit, the relationships between LST and spatial pattern metrics, including both percent cover and configuration, became stronger. The spatial pattern of tree cover also explained more variation in LST. We did not find a "best" size of analytical unit, at which the correlations (or $\mathrm{R}^{2}$ ) peaked, and a turning point occurred (Liu and Weng, 2009; Peng et al., 2016; Weng et al., 2004). This may be due to the very different data used, as well as the approaches for scaling. Here, the spatial resolution of the image data used to map tree cover was $1 \mathrm{~m}$, but most previous studies used the $30 \mathrm{~m}$ Landsat TM data.

\section{Conclusions}

Urban greenspace, particularly trees, has significant cooling effects on urban heat. It is widely recognized that increasing percent coverage of greenspace can greatly reduce ambient air temperatures and land surface temperatures in urban environments. However, recent studies investigating the effects of spatial configuration of greenspace show significant, but inconsistent results, including the direction of the effects. To investigate the causes of this inconsistency, we conducted a comparison study of Baltimore, MD and Sacramento, CA, USA, two cities with very different climatic conditions, using different statistical approaches and analytical units with varied sizes. We found: (1) trees' cooling efficiency generally was higher in Baltimore than in the hotter and drier Sacramento. (2) The effects of spatial configuration of trees on LST varied greatly in terms of magnitude, significance, and even direction, between the two cities, suggesting spatial configuration of trees may play different roles in cities with different climatic conditions. Percent cover of trees was more important than their spatial configuration in predicting LST in Baltimore, but the opposite was found in Sacramento. Therefore, urban planners and managers should be cautious about directly applying results found in cities with different climatic conditions. (3) When using different statistical approaches, the relationships between LST and configuration metrics could dramatically change. Our results underscore the necessity of controlling the effects of percent cover of trees, when quantifying the effects of spatial configuration of trees on LST. These results contribute to the understanding of the inconsistent results from previous studies, which may be caused by the different methods applied (e.g., Pearson correlation analysis versus partial correlation). (4) Spatial autocorrelation could influence the relationships between landscape metrics and LST, particularly when the unit of analysis is relatively small. (5) With the increase of the size of analytical unit, the relationships between spatial configuration metrics and LST became stronger. This study can enhance the understanding on the effects of spatial configuration of greenspace on UHI. It also provides important insights to urban planners and natural resource managers on how to mitigate the impact of urbanization on UHI through urban design and vegetation management.

\section{Acknowledgments}

The support of the National Natural Science Foundation of China (41422104 and 41371197) and the One Hundred Talents program of Chinese Academy of Sciences (29BR2013002) is gratefully acknowledged.

\section{Appendix A. Appendix}

Table A1

A descriptive statistics of LST and landscape metrics of trees.

\begin{tabular}{|c|c|c|c|c|c|c|c|c|c|c|c|c|c|}
\hline \multirow[t]{2}{*}{ City } & \multirow[t]{2}{*}{ Scale } & \multicolumn{2}{|l|}{ LST } & \multicolumn{2}{|l|}{ PTree } & \multicolumn{2}{|c|}{ AREA_MN } & \multicolumn{2}{|c|}{ SHAPE_MN } & \multicolumn{2}{|l|}{ ED } & \multicolumn{2}{|l|}{ LPI } \\
\hline & & Mean & SD & Mean & SD & Mean & SD & Mean & SD & Mean & SD & Mean & SD \\
\hline \multirow[t]{6}{*}{ Baltimore } & 120 & 31.87 & 4.14 & 27.51 & 24.45 & 950.02 & 2267.63 & 1.37 & 0.40 & $57,518.11$ & $33,468.78$ & 19.25 & 23.91 \\
\hline & 360 & 31.87 & 3.83 & 28.11 & 20.52 & 1191.00 & 3949.92 & 1.37 & 0.17 & $52,488.62$ & $24,066.84$ & 14.66 & 19.97 \\
\hline & 600 & 31.87 & 3.56 & 28.13 & 18.73 & 980.78 & 2740.28 & 1.35 & 0.08 & $51,759.32$ & $21,151.46$ & 12.34 & 17.99 \\
\hline & 840 & 31.78 & 3.40 & 28.83 & 17.71 & 866.37 & 1379.75 & 1.35 & 0.07 & $52,364.87$ & $19,491.47$ & 11.50 & 17.04 \\
\hline & 1080 & 31.68 & 3.28 & 29.73 & 16.89 & 901.85 & 1933.74 & 1.34 & 0.06 & $53,401.59$ & $18,325.08$ & 11.26 & 16.30 \\
\hline & city & 31.87 & 4.14 & 27.10 & & 599.60 & $19,526.35$ & 1.32 & 0.54 & 478.26 & & 2.14 & \\
\hline \multirow[t]{6}{*}{ Sacramento } & 120 & 33.27 & 2.97 & 16.93 & 15.10 & 81.65 & 243.84 & 1.25 & 0.41 & $90,008.97$ & $62,935.26$ & 6.82 & 9.99 \\
\hline & 360 & 33.28 & 2.56 & 17.29 & 12.87 & 79.54 & 81.49 & 1.32 & 0.15 & $88,252.77$ & $51,997.52$ & 3.43 & 6.04 \\
\hline & 600 & 33.31 & 2.35 & 17.42 & 12.12 & 80.66 & 73.43 & 1.33 & 0.09 & $87,813.52$ & $47,579.94$ & 2.39 & 4.94 \\
\hline & 840 & 33.35 & 2.18 & 17.41 & 11.49 & 80.57 & 67.24 & 1.32 & 0.06 & $87,552.63$ & $44,935.50$ & 1.87 & 3.66 \\
\hline & 1080 & 33.30 & 2.06 & 18.00 & 10.81 & 81.28 & 57.09 & 1.33 & 0.05 & $89,677.74$ & $42,027.10$ & 1.72 & 3.43 \\
\hline & city & 33.27 & 2.97 & 16.66 & & 73.80 & 1098.00 & 1.39 & 3.33 & 819.85 & & 0.03 & \\
\hline
\end{tabular}


Table A2

Partial correlation between mean patch size and edge density controlling for the effect of percent cover of trees.

\begin{tabular}{|c|c|c|}
\hline & Baltimore & Sacramento \\
\hline 120 & $-0.655^{* *}$ & $-0.438^{* *}$ \\
\hline 360 & $-0.475^{* *}$ & $-0.746^{* *}$ \\
\hline 600 & $-0.454^{* *}$ & $-0.789^{* *}$ \\
\hline 840 & $-0.643^{* *}$ & $-0.807^{* *}$ \\
\hline 1080 & $-0.528^{* *}$ & $-0.846^{* *}$ \\
\hline
\end{tabular}

${ }^{* *} P<0.01$ (2-tailed)

Table A3

Correlation matrix between independent variables in Baltimore.

\begin{tabular}{|c|c|c|c|c|c|c|}
\hline Scale & & PTree & AREA_MN & SHAPE_MN & ED & LPI \\
\hline \multirow[t]{5}{*}{$120 \mathrm{~m}$} & PTree & 1 & & & & \\
\hline & AREA_MN & $0.70^{* *}$ & 1 & & & \\
\hline & SHAPE_MN & $0.51^{* *}$ & $0.31^{* *}$ & 1 & & \\
\hline & $\mathrm{ED}$ & $0.66^{* *}$ & $0.11^{* *}$ & $0.54^{* *}$ & 1 & \\
\hline & LPI & $0.95^{* *}$ & $0.78^{* *}$ & $0.45^{* *}$ & $0.45^{* *}$ & 1 \\
\hline \multirow{5}{*}{$360 \mathrm{~m}$} & PTree & 1 & & & & \\
\hline & AREA_MN & $0.53^{* *}$ & 1 & & & \\
\hline & SHAPE_MN & $0.61^{* *}$ & $0.46^{* *}$ & 1 & & \\
\hline & ED & $0.61^{* *}$ & 0.00 & $0.44^{* *}$ & 1 & \\
\hline & LPI & $0.91^{* *}$ & $0.61^{* *}$ & $0.52^{* *}$ & $0.31^{* *}$ & 1 \\
\hline \multirow[t]{5}{*}{$600 \mathrm{~m}$} & PTree & 1 & & & & \\
\hline & AREA_MN & $0.54^{* *}$ & 1 & & & \\
\hline & SHAPE_MN & $0.73^{* *}$ & $0.50^{* *}$ & 1 & & \\
\hline & ED & $0.62^{* *}$ & $0.04^{*}$ & $0.53^{* *}$ & 1 & \\
\hline & LPI & $0.88^{* *}$ & $0.64^{* *}$ & $0.52^{* *}$ & $0.29^{* *}$ & 1 \\
\hline \multirow[t]{5}{*}{$840 \mathrm{~m}$} & PTree & 1 & & & & \\
\hline & AREA_MN & $0.76^{* *}$ & 1 & & & \\
\hline & SHAPE_MN & $0.72^{* *}$ & $0.46^{* *}$ & 1 & & \\
\hline & $\mathrm{ED}$ & $0.63^{* *}$ & 0.16 & $0.65^{* *}$ & 1 & \\
\hline & LPI & $0.87^{* *}$ & $0.87^{* *}$ & $0.45^{* *}$ & $0.27^{* *}$ & 1 \\
\hline \multirow[t]{5}{*}{$1080 \mathrm{~m}$} & PTree & 1 & & & & \\
\hline & AREA_MN & $0.60^{* *}$ & 1 & & & \\
\hline & SHAPE_MN & $0.72^{* *}$ & $0.34^{* *}$ & 1 & & \\
\hline & ED & $0.62^{* *}$ & 0.05 & $0.67^{* *}$ & 1 & \\
\hline & LPI & $0.86^{* *}$ & $0.71^{* *}$ & $0.40^{* *}$ & $0.25^{* *}$ & 1 \\
\hline
\end{tabular}

${ }^{* *} P<0.01,{ }^{*} P<0.05$ (2-tailed).

Table A4

Correlation matrix between independent variables in Sacramento.

\begin{tabular}{|c|c|c|c|c|c|c|}
\hline Scale & & PTree & AREA_MN & SHAPE_MN & ED & LPI \\
\hline \multirow[t]{5}{*}{$120 \mathrm{~m}$} & Ptree & 1 & & & & \\
\hline & AREA_MN & $0.40^{* *}$ & 1 & & & \\
\hline & SHAPE_MN & $0.44^{* *}$ & $0.20^{* *}$ & 1 & & \\
\hline & ED & $0.85^{* *}$ & $0.12^{* *}$ & $0.48^{* *}$ & 1 & \\
\hline & LPI & $0.84^{* *}$ & $0.52^{* *}$ & $0.31^{* *}$ & $0.50^{* *}$ & 1 \\
\hline \multirow[t]{5}{*}{$360 \mathrm{~m}$} & PTree & 1 & & & & \\
\hline & AREA_MN & $0.67^{* *}$ & 1 & & & \\
\hline & SHAPE_MN & $0.41^{* *}$ & $0.38^{* *}$ & 1 & & \\
\hline & $\mathrm{ED}$ & $0.87^{* *}$ & $0.31^{* *}$ & $0.40^{* *}$ & 1 & \\
\hline & LPI & $0.70^{* *}$ & $0.76^{* *}$ & $0.19^{* *}$ & $0.36^{* *}$ & 1 \\
\hline \multirow[t]{5}{*}{$600 \mathrm{~m}$} & PTree & 1 & & & & \\
\hline & AREA_MN & $0.69^{* *}$ & 1 & & & \\
\hline & SHAPE_MN & $0.48^{* *}$ & $0.46^{* *}$ & 1 & & \\
\hline & ED & $0.87^{* *}$ & $0.32^{* *}$ & $0.44^{* *}$ & 1 & \\
\hline & LPI & $0.61^{* *}$ & $0.72^{* *}$ & $0.14^{* *}$ & $0.28^{* *}$ & 1 \\
\hline \multirow[t]{5}{*}{$840 \mathrm{~m}$} & PTree & 1 & & & & \\
\hline & AREA_MN & $0.70^{* *}$ & 1 & & & \\
\hline & SHAPE_MN & $0.69^{* *}$ & $0.57^{* *}$ & 1 & & \\
\hline & ED & $0.88^{* *}$ & $0.34^{* *}$ & $0.65^{* *}$ & 1 & \\
\hline & LPI & $0.61^{* *}$ & $0.75^{* *}$ & $0.22^{* *}$ & $0.28^{* *}$ & 1 \\
\hline \multirow[t]{5}{*}{$1080 \mathrm{~m}$} & PTree & 1 & & & & \\
\hline & AREA_MN & $0.73^{* *}$ & 1 & & & \\
\hline & SHAPE_MN & $0.69^{* *}$ & $0.62^{* *}$ & 1 & & \\
\hline & ED & $0.88^{* *}$ & $0.38^{* *}$ & $0.64^{* *}$ & 1 & \\
\hline & LPI & $0.57^{* *}$ & $0.69^{* *}$ & $0.21^{*}$ & $0.27^{* *}$ & 1 \\
\hline
\end{tabular}

${ }^{* *} P<0.01,{ }^{*} P<0.05$ (2-tailed). 

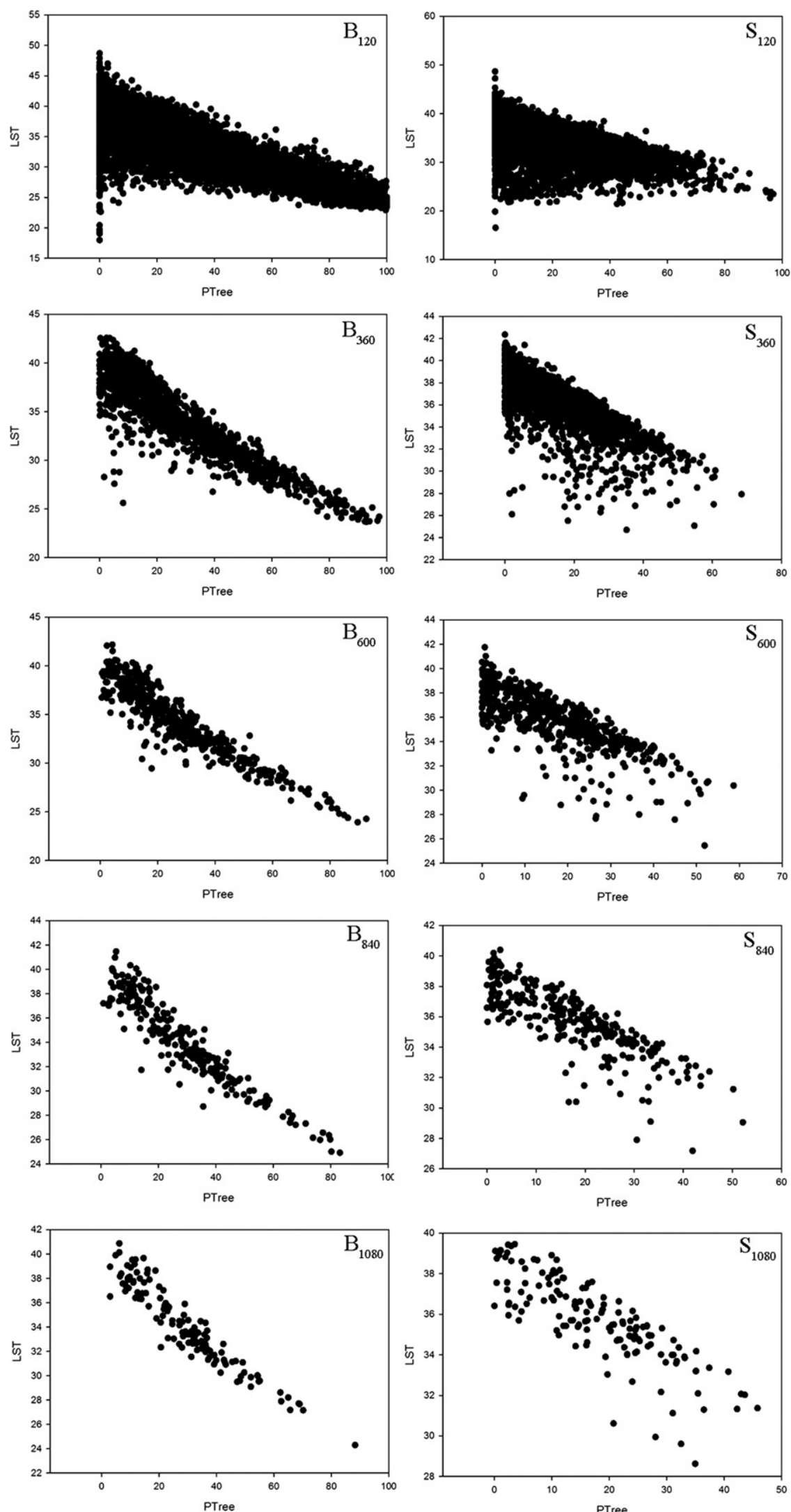

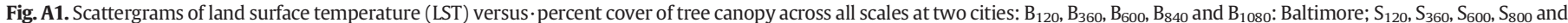
$\mathrm{S}_{1080}$ : Sacramento. 


\section{References}

Akbari, H., Rosenfeld, A., Taha, H., Gartland, L., 1996. Mitigation of summer urban heat islands to save electricity and smog. 76th Annual Meteorological Society Meeting. GA, Atlanta.

Akbari, H., Pomerantz, M., Taha, H., 2001. Cool surfaces and shade trees to reduce energy use and improve air quality in urban areas. Sol. Energy 70, 295-310.

Anderson, M.J., Gribble, N.A., 1998. Partitioning the variation among spatial, temporal and environmental components in a multivariate data set. Aust. J. Ecol. 23, 158-167.

Anselin, L., 2005a. Exploring Spatial Data With GeoDa ${ }^{\mathrm{TM}}$ : A Workbook. University of Illinois, Urbana.

Anselin, L., 2005b. Spatial Regression Analysis in R: A Workbook. University of Illinois, Urbana.

Arnfield, A.J., 2003. Two decades of urban climate research: a review of turbulence, exchanges of energy and water, and the urban heat island. Int. J. Climatol. 23, 1-26.

Asgarian, A., Amiri, B.J., Sakieh, Y., 2015. Assessing the effect of green cover spatial patterns on urban land surface temperature using landscape metrics approach. Urban Ecosystems 18, 209-222.

Barsi, J.A., Schott, J.R., Palluconi, F.D., Hook, S.J., 2005. Validation of a web-based atmospheric correction tool for single thermal band instruments. Optics \& Photonics 2005. International Society for Optics and Photonics (pp. 58820E-58820E-58827).

Bowler, D.E., Buyung-Ali, L., Knight, T.M., Pullin, A.S., 2010. Urban greening to cool towns and cities: a systematic review of the empirical evidence. Landsc. Urban Plan. 97, 147-155.

Brazel, A., Selover, N., Vose, R., Heisler, G., 2000. The tale of two climates-Baltimore and Phoenix urban LTER sites. Clim. Res. 15, 123-135.

Buyantuyev, A., Wu, J.G., 2010. Urban heat islands and landscape heterogeneity: linking spatiotemporal variations in surface temperatures to land-cover and socioeconomic patterns. Landsc. Ecol. 25, 17-33.

Cadenasso, M.L., Pickett, S.T., Weathers, K.C., Jones, C.G., 2003. A framework for a theory of ecological boundaries. Bioscience 53, 750-758.

Cao, X., Onishi, A., Chen, J., Imura, H., 2010. Quantifying the cool island intensity of urban parks using ASTER and IKONOS data. Landsc. Urban Plan. 96, 224-231.

Chander, G., Markham, B., 2003. Revised Landsat-5 TM radiometric calibration procedures and postcalibration dynamic ranges. IEEE Trans. Geosci. Remote Sens. 41, 2674-2677.

Chander, G., Markham, B.L., Helder, D.L., 2009. Summary of current radiometric calibration coefficients for Landsat MSS, TM, ETM + , and EO-1 ALI sensors. Remote Sens. Environ. 113, 893-903.

Chen, A.L., Yao, X.A., Sun, R.H., Chen, L.D., 2014. Effect of urban green patterns on surface urban cool islands and its seasonal variations. Urban For. Urban Green. 13, 646-654.

Connors, J.P., Galletti, C.S., Chow, W.T.L, 2013. Landscape configuration and urban heat is land effects: assessing the relationship between landscape characteristics and lan surface temperature in Phoenix, Arizona. Landsc. Ecol. 28, 271-283.

Dugord, P.-A., Lauf, S., Schuster, C., Kleinschmit, B., 2014. Land use patterns, temperature distribution, and potential heat stress risk - the case study Berlin, Germany. Comput. Environ. Urban. Syst. 48, 86-98.

Fan, C., Myint, S.W., Zheng, B.J., 2015. Measuring the spatial arrangement of urban vegetation and its impacts on seasonal surface temperatures. Prog. Phys. Geogr. 39, 199-219.

Fouillet, A., Rey, G., Laurent, F., Pavillon, G., Bellec, S., Guihenneuc-Jouyaux, C., Clavel, J., Jougla, E., Hémon, D., 2006. Excess mortality related to the August 2003 heat wave in France. Int. Arch. Occup. Environ. Health 80, 16-24.

Gustafson, E.J., 1998. Quantifying landscape spatial pattern: what is the state of the art? Ecosystems 1, 143-156.

Hamada, S., Ohta, T., 2010. Seasonal variations in the cooling effect of urban green areas on surrounding urban areas. Urban For. Urban Green. 9, 15-24.

Harlan, S.L., Ruddell, D.M., 2011. Climate change and health in cities: impacts of heat and air pollution and potential co-benefits from mitigation and adaptation. Curr. Opin. Environ. Sustain. 3, 126-134.

Heikkinen, R.K., Luoto, M., Kuussaari, M., Poyry, J., 2005. New insights into butterflyenvironment relationships using partitioning methods. Proc. Biol. Sci. 272 2203-2210.

Huang, G., Cadenasso, M.L., 2016. People, landscape, and urban heat island: dynamics among neighborhood social conditions, land cover and surface temperatures. Landsc. Ecol. 31, 2507-2515.

Huang, G.L., Zhou, W.Q., Cadenasso, M.L., 2011. Is everyone hot in the city? Spatial pattern of land surface temperatures, land cover and neighborhood socioeconomic characteristics in Baltimore, MD. J. Environ. Manag. 92, 1753-1759.

Imhoff, M.L., Zhang, P., Wolfe, R.E., Bounoua, L., 2010. Remote sensing of the urban heat island effect across biomes in the continental USA. Remote Sens. Environ. 114 504-513.

Jenerette, G.D., Harlan, S.L., Brazel, A., Jones, N., Larsen, L., Stefanov, W.L., 2007. Regional relationships between surface temperature, vegetation, and human settlement in a rapidly urbanizing ecosystem. Landsc. Ecol. 22, 353-365.

Jenerette, G.D., Harlan, S.L., Buyantuev, A., Stefanov, W.L., Declet-Barreto, J., Ruddell, B.L., Myint, S.W., Kaplan, S., Li, X., 2016. Micro-scale urban surface temperatures are related to land-cover features and residential heat related health impacts in Phoenix, AZ USA. Landsc. Ecol. 31, 745-760.

Kong, F.H., Yin, H.W., Wang, C.Z., Cavan, G., James, P., 2014. A satellite image-based analysis of factors contributing to the green-space cool island intensity on a city scale. Urban For. Urban Green. 13, 846-853.

Lambers, H., Chapin III, F.S., Pons, T.L., 2008. Plant Physiological Ecology. Springer, New York, pp. 163-217.

Landsat Project Science Office, 2009. Landsat 7 Science Data Users Handbook. Goddard Space Flight Center, NASA, Washington, DC (URL: http://landsathandbook.gsfc.nasa. gov/handbook.html).
Lee, S.W., Hwang, S.J., Lee, S.B., Hwang, H.S., Sung, H.C., 2009. Landscape ecological approach to the relationships of land use patterns in watersheds to water quality characteristics. Landsc. Urban Plan. 92, 80-89.

Li, H.B., Wu, J.G., 2004. Use and misuse of landscape indices. Landsc. Ecol. 19, 389-399.

Li, S.C., Zhao, Z.Q., Xie, M.M., Wang, Y.L., 2010. Investigating spatial non-stationary and scale-dependent relationships between urban surface temperature and environmental factors using geographically weighted regression. Environ. Model. Softw. 25, $1789-1800$

Li, J.X., Song, C.H., Cao, L., Zhu, F.G., Meng, X.L., Wu, J.G., 2011. Impacts of landscape structure on surface urban heat islands: a case study of Shanghai, China. Remote Sens. Environ. 115, 3249-3263.

Li, X.M., Zhou, W.Q., Ouyang, Z.Y., Xu, W.H., Zheng, H., 2012. Spatial pattern of greenspace affects land surface temperature: evidence from the heavily urbanized Beijing metropolitan area, China. Landsc. Ecol. 27, 887-898.

Li, X., Zhou, W., Ouyang Z., 2013a. Forty years of urban expansion in Beijing: what is the relative importance of physical, socioeconomic, and neighborhood factors? Appl. Geogr. 38, 1-10

Li, X.M., Zhou, W.Q., Ouyang, Z.Y., 2013b. Relationship between land surface temperature and spatial pattern of greenspace: what are the effects of spatial resolution? Landsc. Urban Plan. 114, 1-8.

Li, W.F., Bai, Y., Chen, Q.W., He, K., Ji, X.H., Han, C.M., 2014. Discrepant impacts of land use and land cover on urban heat islands: a case study of Shanghai, China. Ecol. Indic. 47, $171-178$

Li, X.X., Li, W.W., Middel, A., Harlan, S., Brazel, A., Turner, B., 2016. Remote sensing of the surface urban heat island and land architecture in Phoenix. Arizona: combined effects of land composition and configuration and cadastral-demographic-economic factors. Remote Sens. Environ. 174, 233-243.

Lichstein, J.W., Simons, T.R., Shriner, S.A., Franzreb, K.E., 2002. Spatial autocorrelation and autoregressive models in ecology. Ecol. Monogr. 72, 445-463.

Liu, H., Weng, Q.H., 2009. Scaling effect on the relationship between landscape pattern and land surface temperature: a case study of Indianapolis, United States. Photogramm. Eng. Remote. Sens. 75, 291-304.

Ma, Y., Kuang, Y.Q., Huang, N.S., 2010. Coupling urbanization analyses for studying urban thermal environment and its interplay with biophysical parameters based on TM/ ETM plus imagery. Int. J. Appl. Earth Obs. Geoinf. 12, 110-118.

MacFaden, S.W., O'Neil-Dunne, J.P.M., Royar, A.R., Lu, J.W.T., Rundle, A.G., 2012. High-resolution tree canopy mapping for New York City using LIDAR and object-based image analysis. J. Appl. Remote. Sens. 6, 1-23.

Maimaitiyiming, M., Ghulam, A., Tiyip, T., Pla, F., Latorre-Carmona, P., Halik, U., Sawut, M., Caetano, M., 2014. Effects of green space spatial pattern on land surface temperature: implications for sustainable urban planning and climate change adaptation. ISPRS J. Photogramm. Remote Sens. 89, 59-66.

McCarthy, H.R., Pataki, D.E., Jenerette, G.D., 2011. Plant water-use efficiency as a metric of urban ecosystem services. Ecol. Appl. 21, 3115-3127.

McGarigal, K., Cushman, S., Neel, M., Ene, E., 2002. FRAGSTATS: spatial pattern analysis program for categorical maps. Computer Software Program Produced by the Authors at the University of Massachusetts, Amherst (Available at the following web site:). http://www.umass.edu/landeco/research/fragstats/fragstats.

Myint, S.W., Zheng, B.J., Talen, E., Fan, C., Kaplan, S., Middel, A., Smith, M., Huang, H.-P., Brazel, A., 2015. Does the spatial arrangement of urban landscape matter? Examples of urban warming and cooling in Phoenix and Las Vegas. Ecosystem Health Sustain. 1, $1-15$.

Niemelä, J., 1999. Ecology and urban planning. Biodivers. Conserv. 8, 119-131.

Pataki, D.E., McCarthy, H.R., Litvak, E., Pincetl, S., 2011. Transpiration of urban forests in the Los Angeles metropolitan area. Ecol. Appl. 21, 661-677.

Peng, J., Wang, Y.L., Zhang, Y., Wu, J.S., Li, W.F., Li, Y., 2010. Evaluating the effectiveness of landscape metrics in quantifying spatial patterns. Ecol. Indic. 10, 217-223.

Peng, J., Xie, P., Liu, Y.X., Ma, J., 2016. Urban thermal environment dynamics and associated landscape pattern factors: a case study in the Beijing metropolitan region. Remote Sens. Environ. 173, 145-155.

Polsky, C., Grove, J.M., Knudson, C., Groffman, P.M., Bettez, N., Cavender-Bares, J., Hall, S.J., Heffernan, J.B., Hobbie, S.E., Larson, K.L., 2014. Assessing the homogenization of urban land management with an application to US residential lawn care. Proc. Natl. Acad. Sci. 111, 4432-4437.

Poumadere, M., Mays, C., Le Mer, S., Blong, R., 2005. The 2003 heat wave in France: dangerous climate change here and now. Risk Anal. 25, 1483-1494.

R Development Core Team, 2011. R: A Language and Environment for Statistical Computing. Version 2.12.1R Foundation for Statistical Computing, Vienna.

R. Team, 2011. A Language and Environment for Statistical Computing. R Development Core Team.

Rhee, J., Park, S., Lu, Z., 2014. Relationship between land cover patterns and surface temperature in urban areas. Geosci. Remote Sens. Lett. 51, 521-536.

Riitters, K.H., O'Neill, R.V., Hunsaker, C.T., Wickham, J.D., Yankee, D.H., Timmins, S.P., Jones, K.B., Jackson, B.L., 1995. A factor analysis of landscape pattern and structure metrics. Landsc. Ecol. 10, 23-39.

Santamouris, M., Cartalis, C., Synnefa, A., Kolokotsa, D., 2015. On the impact of urban heat island and global warming on the power demand and electricity consumption of buildings-a review. Energ. Buildings 98, 119-124.

Schulze, E.-D., Beck, E., Müller-Hohenstein, K., 2005. Plant Ecology. Springer, Berlin, pp. 253-379.

Sobrino, J.A., Jiménez-Muñoz, J.C., Paolini, L., 2004. Land surface temperature retrieval from LANDSAT TM 5. Remote Sens. Environ. 90, 434-440.

Sun, R.H., Chen, L.D., 2017. Effects of green space dynamics on urban heat islands: Mitigation and diversification. Ecosyst. Serv. 23, 38-46. 
Tayyebi, A., Darrel Jenerette, G., 2016. Increases in the climate change adaption effectiveness and availability of vegetation across a coastal to desert climate gradient in metropolitan Los Angeles, CA, USA. Sci. Total Environ. 548-549, 60-71.

Voogt, J.A., Oke, T.R., 2003. Thermal remote sensing of urban climates. Remote Sens. Environ. 86, 370-384.

Wan, K.K.W., Li, D.H.W., Pan, W.Y., Lam, J.C., 2012. Impact of climate change on building energy use in different climate zones and mitigation and adaptation implications. Appl. Energy 97, 274-282.

Wang, H., Ouyang, Z., Chen, W., Wang, X., Zheng, H., Ren, Y., 2011. Water, heat, and airborne pollutants effects on transpiration of urban trees. Environ. Pollut. 159, 2127-2137.

Weng, Q.H., 2009. Thermal infrared remote sensing for urban climate and environmental studies: methods, applications, and trends. ISPRS J. Photogramm. Remote Sens. 64, 335-344.

Weng, Q.H., Lu, D.S., Schubring, J., 2004. Estimation of land surface temperature-vegetation abundance relationship for urban heat island studies. Remote Sens. Environ. $89,467-483$

Weng, Q.H., Lu, D.S., Liang, B.Q., 2006. Urban surface biophysical descriptors and land surface temperature variations. Photogramm. Eng. Remote. Sens. 72, 1275-1286.

White, M.A., Nemani, R.R., Thornton, P.E., Running, S.W., 2002. Satellite evidence of phenological differences between urbanized and rural areas of the eastern United States deciduous broadleaf forest. Ecosystems 5, 260-273.

Wu, H., Ye, L.P., Shi, W.Z., Clarke, K.C., 2014. Assessing the effects of land use spatial structure on urban heat islands using HJ-1B remote sensing imagery in Wuhan, China. Int. J. Appl. Earth Obs. Geoinf. 32, 67-78.

Xie, M.M., Wang, Y.L., Chang, Q., Fu, M.C., Ye, M.T., 2013. Assessment of landscape patterns affecting land surface temperature in different biophysical gradients in Shenzhen, China. Urban Ecosystems 16, 871-886.
Yan, H., Fan, S.X., Guo, C.X., Wu, F., Zhang, N., Dong, L., 2014. Assessing the effects of landscape design parameters on intra-urban air temperature variability: the case of Beijing, China. Build. Environ. 76, 44-53.

Yokohari, M., Brown, R.D., Kato, Y., Moriyama, H., 1997. Effects of paddy fields on summertime air and surface temperatures in urban fringe areas of Tokyo, Japan. Landsc. Urban Plan. 38, 1-11.

Yuan, F., Bauer, M.E., 2007. Comparison of impervious surface area and normalized difference vegetation index as indicators of surface urban heat island effects in Landsat imagery. Remote Sens. Environ. 106, 375-386.

Zhang, X.Y., Zhong, T.Y., Feng, X.Z., Wang, K., 2009. Estimation of the relationship between vegetation patches and urban land surface temperature with remote sensing. Int J. Remote Sens. 30, 2105-2118.

Zhou, W.Q., Troy, A., 2008. An object-oriented approach for analysing and characterizing urban landscape at the parcel level. Int. J. Remote Sens. 29, 3119-3135.

Zhou, W.Q., Troy, A., Grove, M., 2008. Modeling residential lawn fertilization practices: in tegrating high resolution remote sensing with socioeconomic data. Environ. Manag. 41, 742-752.

Zhou, W.Q., Huang, G.L., Cadenasso, M.L., 2011. Does spatial configuration matter? Understanding the effects of land cover pattern on land surface temperature in urban landscapes. Landsc. Urban Plan. 102, 54-63.

Zhou, W.Q., Qian, Y.G., Li, X.M., Li, W.F., Han, L.J., 2014. Relationships between land cover and the surface urban heat island: seasonal variability and effects of spatial and thematic resolution of land cover data on predicting land surface temperatures. Landsc. Ecol. 29, 153-167.

Zhou, W.Q., Pickett, S.T.A., Cadenasso, M.L., 2016. Shifting concepts of urban spatial heterogeneity and their implications for sustainability. Landsc. Ecol. 1-16. 